\title{
Revising the fundamentals of ecological knowledge: the biota-environment interaction
}

\author{
Victor G. Gorshkov ${ }^{a}$, Anastassia M. Makarieva ${ }^{a, *}$, Vadim V. Gorshkov ${ }^{b}$ \\ ${ }^{a}$ Theoretical Physics Division, Petersburg Nuclear Physics Institute, 188300 Gatchina, St. Petersburg, Russia \\ ${ }^{\mathrm{b}}$ Ecology of Plant Communities Laboratory, Komarov Botanical Institute, 197367, 2 Prof. Popov Str., St. Petersburg, Russia
}

Received 8 March 2003; received in revised form 20 August 2003; accepted 30 September 2003

\begin{abstract}
The foundations of ecological science were laid down at those times when the problem of a possible loss of local and global environmental sustainability was not as acute as it has become today. To make sure that the proposed scientific solutions to this problem are responsible, it is useful to revise the existing frameworks of environmental thought. In this paper, we present quantitative evidence suggesting that the persistence of an environment suitable for life for any appreciable period of time is only possible as long as a substantial area on the planet's surface is occupied by natural ecosystems undisturbed by anthropogenic activities. Once the natural biotic mechanism of environmental control is destroyed, both local and global environment rapidly (over a time scale of hundreds of years) degrade to a state unfit for life, even if any direct anthropogenic environmental impact like industrial pollution is absent. It is therefore important to quantitatively assess the stabilizing impact of natural ecosystems and to determine the necessary and sufficient global area that must be exempted from anthropogenic activities and let be occupied by natural ecosystems, so that the latter have power enough to sustain the global environment in a stable life-compatible state. This urgent scientific task emerges as the major challenge for modern ecological science. We discuss how the proposed conceptual approach to the biota-environment interaction relates to the important paradigms of biological theory.
\end{abstract}

(c) 2003 Elsevier B.V. All rights reserved.

Keywords: Biotic regulation of the environment; Competitive interaction; Self-organization; Productivity; Climate stability; Genetic adaptation; Ecological community

\section{Introduction}

Environmental problems of the humanity are of recent origin. As long as the world's population remained small, the global environmental impact of humans was negligible. On a local scale, when the local environment declined to a degree prohibiting human

\footnotetext{
* Corresponding author. Tel.: +7-812-7131963; fax: +7-812-7131963.

E-mail address: elba@infopro.spb.su (A.M. Makarieva).
}

existence, one could move to new unexploited territories. Nowadays, the world's population is such that the environmental impact of industrial and agricultural activities is globally significant. People have occupied most part of habitable territories, and there is nowhere to escape from local environmental degradation. It has become important to learn how to keep the hospitable environment stable both on a local and global scale.

Modern ecological knowledge is rooted in the first observations of primitive hunters, gatherers and farmers. For the most part of human history, ecology as well 
as all other branches of biological science has been predominantly solving the task of feeding and clothing the humans. In the absence of environmental concerns, the growing body of scientific knowledge was primarily built up of those observations that ensured the most efficient exploitation of the biosphere. There were no scientific problems like 'Why do the environmental conditions compatible with human existence persist through time?' The constancy of favorable for humans values of environmental parameters like mean annual temperature, precipitation regime, biological productivity, atmospheric gaseous composition was perceived as something self-evident, comparable to the constancy of the gravitational field of Earth.

The global population number of humans, as well as their environmental impact, are growing according to an exponential law, which dictates the abrupt character of any change. It was only very recently that the natural sciences were challenged with the task of providing recipes for ensuring environmental sustainability. Hence, despite the task is conceptually novel, it is often attempted to be solved on the basis of the old paradigms, simply because there has been no sufficient time to revise them. It is commonly believed that the major ecological problem of the humanity is to cope with the large-scale environmental pollution, like, for example, $\mathrm{CO}_{2}$ emissions due to burning of fossils or contamination of water and soil with industrial wastes. It continues to be implicitly assumed that, as soon as this problem is solved (shift to no-waste technologies and clean energy sources suggests itself as an obvious logical solution), there will be no more grounds to expect any environmental cataclysms. The environment will remain life-compatible 'by itself', as it did before.

In this paper, we aim to show that such an approach to environmental problems can be dangerously misleading in terms of its practical implications. We re-consider logical principles that form the scientific groundwork for this approach. We present quantitative arguments suggesting that the persistence of an environment suitable for humans for any appreciable period of time is only possible as long as natural ecosystems undisturbed by anthropogenic activities occupy a globally significant area. Maintenance of a suitable for humans environment is the unique product of functioning of the natural biota. Once the natural biotic mechanism of environmental control is destroyed, both local and global environment rapidly (over a time scale of hundreds of years) degrade to a state unfit for life.

Quantitative scientific assessment of the stabilizing environmental power of natural biota represents therefore an indispensable step towards environmental sustainability. It will allow to determine the necessary size of territories that should be exempted from anthropogenic activities and returned to natural ecosystems, in order to ensure that the global power of the natural biota is sufficient for supporting the global environment in a stable life-compatible state. From today we are witnessing a global-scale decline of the natural life-support systems and environmental conditions (Steffen et al., 2003), this suggests that modern global biotic regulation power of yet remaining natural ecosystems on land and in the sea is already insufficient for that task.

In Section 2, we show that the existence of biotic regulation of the environment follows unambiguously from numeric considerations of major environmental constituents like organic and inorganic stores of life-important elements, global power of biochemical synthesis and decomposition and characteristic magnitudes of environmental fluctuations. We strengthen the body of evidence in favor of biotic regulation by introducing the problem of intrinsic physical instability of a climate with liquid hydrosphere.

In Section 3, we discuss the fundamental properties of life organization that make biotic regulation possible. We point out that the quantitative gap between the level of orderliness inherent to living systems and that of open dynamic systems of physical nature 'self-organized' at the expense of external energy fluxes reaches more than 20 orders of magnitude. The environmental fluxes of free energy being virtually disordered as compared to living systems, the orderliness of life cannot be maintained by any physical process. To counteract the spontaneous decay of the highly ordered state of life, the living matter must be divided into a sufficiently large number of uniform objects (individuals), among which a competitive interaction is switched on. As soon as the level of orderliness of any given object diminishes below the sensitivity of competitive interaction, such an object loses competitiveness and is replaced by a copy of a normal object retaining the initial high level of order. This process of maintenance of order is unique to living matter and differentiates it from 
the inanimate world. It follows that none internally correlated living object may exist in a single number. Biotic regulation of global environmental conditions should be therefore performed by a large number of operational units featuring a relatively small size. We discuss the likely nature of such ecosystem units and propose that they are formed by individual trees with the attached below- and above-ground biota (bacteria, fungi, under-canopy vegetation, small invertebrates).

The power of physical fluxes of many life-important chemical elements, for example, atmospheric carbon and oxygen, significantly exceeds the power of biochemical processes of synthesis and decomposition. In Section 4, we discuss conditions when biotic regulation of global environmental concentrations of such elements by locally operating ecosystem units is nevertheless possible. We introduce the notions of locally and globally regulated biogens and illustrate them by the examples of soil phosphorus, atmospheric carbon and oxygen. In Section 5, we reveal how the failure to critically revise the existing biological paradigms may facilitate the spontaneous development of the modern civilization towards a global environmental collapse.

\section{The nature of environmental stability on Earth}

\subsection{Environment under biotic impact}

Within the ecological context, environment is defined as a three-dimensional area that is inhabited by living organisms. For any living organism, a suitable for life environment is characterized by narrow intervals of environmental parameters like ambient temperature, pressure, humidity, chemical composition of air and soil, food availability.

Life is based on biochemical reactions that convert inorganic substances stored in the environment into organic ones and back. The existing power of the biochemical fluxes of synthesis and decomposition of organic substances is such that, were not these processes tightly compensating each other, the environment could change dramatically in time periods of several tens of years, reaching a state prohibiting life existence.

We illustrate this statement by the following important example. The global amount of atmospheric $\mathrm{CO}_{2}$ is of the order of $M^{-} \sim 10^{3} \mathrm{GtC}$ (Degens et al., 1984; Holmen, 1992) $\left(1 \mathrm{Gt}=10^{9} \mathrm{t}\right)$. The mean global rates of biochemical synthesis $P^{+}$and decomposition $P^{-}$ are known (with a considerable uncertainty) to be of the order of $P^{+} \sim P^{-} \sim 10^{2} \mathrm{GtC}$ per year (Whittaker and Likens, 1975; Holmen, 1992). If the rates of synthesis and decomposition were largely uncorrelated, for example, if they coincided by the order of magnitude only, their relative difference would be of the order of unity, $\left|P^{+}-P^{-}\right| / P^{ \pm} \sim 1$. In such a case, if synthesis exceeded decomposition, $P^{+}>P^{-}$, the global biota would use up the entire store of atmospheric carbon on a time scale of the order of $M^{-} / P^{-} \sim 10$ years. This would render further photosynthesis and existence of life impossible. The amount of organic carbon in the biosphere (living biomass, humus, and oceanic dissolved organic carbon) is of the same order of magnitude, $M^{+} \sim 10^{3} \mathrm{GtC}$ (Degens et al., 1984; Holmen, 1992). If the rate of decomposition exceeded the rate of synthesis, the global biota would be able to destroy itself completely in equally short periods of time. That is, on a time scale eight orders of magnitude shorter than the age of life (Hayes, 1996; van Zuilen et al., 2002) and $10^{5}$ to $10^{6}$ times shorter than the average period of individual species existence (Stanley, 1979).

It may appear that for a suitable for life environment to persist on a longer time scale, the mean rates of biochemical synthesis and decomposition must precisely coincide. This property of life is commonly referred to as closeness of natural biochemical cycles. By contrast, technological synthesis and decomposition of various civilization products are not correlated and do not compensate each other, thus creating environmental pollution and other disturbances.

But, at a closer look, one recognizes that it is impossible to ensure complete closeness of biochemical cycles. Mathematically, complete closeness of biochemical cycles would mean an exact equality between the mean rates of synthesis $P^{+}$and decomposition $P^{-}$of organic matter. However, synthesis and decomposition of organic matter represent independent biochemical processes that are generally performed by different organisms of the biota and in different environmental conditions (temperature, humidity, etc.). The characteristic global values of $P^{+}$and $P^{-}$ are determined by the individual design, population abundance and overall numbers of autotrophic and 
heterotrophic species inhabiting Earth. It is clear that $P^{+}$and $P^{-}$cannot coincide with an infinite precision.

To visualize this point, one can compare the rates of biochemical synthesis and decomposition to the rates of production and consumption of goods in the human society, while the amount of organic carbon in the environment can be compared to the standing amount of goods in shops. As is well known, the main goal of centrally planned economics of socialistic countries consisted in making the rate of production of goods equal to the rate of their consumption, in order to satisfy the needs of the population by keeping the amount of available goods at an optimum level $M_{\text {opt }}$. As is equally well known, all such attempts failed. An inherent feature of planned economics is that there is either an overproduction of goods, $M^{+} \gg M_{\text {opt }}$, or their severe deficit, $M^{+} \ll M_{\text {opt }}$. It is impossible to maintain a needed value of $M_{\mathrm{opt}}$ (or maintain a suitable for life environment) by trying to equate the mean rates of $P^{+}$and $P^{-}$. This is because production and consumption of goods, as well as biochemical synthesis and decomposition, are complex processes that are governed by a large number of quite independent factors (e.g., industrial power of the country versus its population number). Such processes cannot be forced to coincide in their rates with an infinite precision.

While the rate of biochemical synthesis is limited from above by the power of solar radiation, the rate of decomposition, being ultimately a function of population abundance, is not limited by anything. It may therefore appear that the equality between long-term averages of the rates of synthesis and decomposition and, hence, environmental stability, can be ensured by the limiting principle: The organisms just eat up (decompose) everything that is produced (synthesized). The above example with centrally planned economics helps to reveal the logical flaw of such reasoning. The organisms (consumers in the human society) do not care about the rate at which the biomass (industrial goods) is produced. They deal with the stores of biomass (goods) and consume them at a rate determined by their biological (socioeconomic) peculiarities. The consumption process continues until the biomass (goods) stores are fully used up. It is clear therefore that there is only one value of the amount of organic biomass that could be sustainably maintained by the limiting principle, it is $M^{+}=0$. However, this value is life-incompatible. It corresponds to the state of complete absence of organic biomass, i.e., self-destruction of life. (The same logic can be applied for inorganic stores of matter $M^{-}$that are consumed by autotrophs.)

Even if the mean global rates of synthesis and decomposition coincided, say, to a high accuracy of $1 \%$, $\alpha \equiv\left|P^{+}-P^{-}\right| / P^{ \pm} \sim 0.01$, such a biota would completely destroy its environment (or self-destroy) in $M^{ \pm} /\left|P^{+}-P^{-}\right|=M^{ \pm} /\left(\alpha P^{ \pm}\right) \sim 10^{3}$ years, i.e., nearly instantaneously on a geological scale. The life span of the biota would be short for any realistic accuracy of the coincidence of $P^{+}$and $P^{-}$. To extend the biotic life span to the documented several billion years of life existence, $T \sim 10^{9}$ years, one has to demand that the living organisms and their ecological communities are designed such that the mean rates of synthesis and decomposition performed by them coincide to an accuracy of $\alpha=M^{ \pm} /\left(P^{ \pm} T\right) \sim 10^{-8}$, which is, of course, improbable.

There is only one way to ensure that life persists on a practically infinite time scale comparable to that of the Universe itself (more than 3 billion years (Hayes, 1996; van Zuilen et al., 2002) versus 11-20 billion years (Krauss and Chaboyer, 2003)).

It is to organize the biota in such a manner that it would react to any environmental change as soon as its relative magnitude exceeds some critical value, which can be naturally called biotic sensitivity $\varepsilon_{\mathrm{b}}$. As long as the magnitude of the environmental change remains lower than biotic sensitivity, synthesis and decomposition of organic matter by the biota may proceed in an uncorrelated manner featuring quite different rates. However, as soon as some environmental parameter changes by $\varepsilon_{\mathrm{b}}$, the biota initiates compensating processes and keeps them going until the disturbance is diminished to a level below $\varepsilon_{\mathrm{b}}$, when the biota no longer notices it. (The optimal state to which the environment ultimately returns can be therefore defined to an accuracy of $\varepsilon_{\mathrm{b}}$.)

For example, if the amount of inorganic carbon in the atmosphere changes by $\varepsilon_{\mathrm{b}} \sim 1 \%$ (e.g., increases), the biota can enhance the rate of biochemical synthesis (thus accelerating $\mathrm{CO}_{2}$ removal from the atmosphere) or reduce the rate of biochemical decomposition (thus diminishing $\mathrm{CO}_{2}$ release) until the perturbed concentration relaxes to its optimal value. The same principle can be used to control temperature, humidity or any other environmental parameters. We will further refer 
to this pattern of biota-environment interaction as biotic regulation of the environment (Gorshkov, 1986, 1995; Gorshkov et al., 2000).

\subsection{Environment under impact of physicochemical processes}

Apart from biochemical cycles of matter, the environment is affected by various abiotic physicochemical processes. For example, there are continuous fluxes of emission of inorganic carbon from the Earth's interior (e.g., due to volcanic activity) and deposition of inorganic carbon in sediments (e.g., in the course of weathering). These fluxes arise due to different physicochemical processes and do not compensate each other. The rate of weathering is also to a certain degree influenced by the biota (Schwartzman and Volk, 1989; Schwartzman, 1999; Lenton and von Blohe, 2001). However, the process of weathering does not compensate the independent process of inorganic carbon emission from the Earth's core. The latter appears more powerful than the former (Degens et al., 1984; Holmen, 1992). The mean global Phanerozoic net flux of inorganic carbon emission is of the order of $10^{-2} \mathrm{GtC}$ per year (Degens et al., 1984). This rate is four orders of magnitude lower than the rate of global biochemical fluxes of synthesis and decomposition of organic matter. Although the abiotic processes of carbon emission are indeed able to significantly alter the environment, they would do so four orders of magnitude more slowly than the biota itself could do.

When the amount of inorganic carbon in the atmosphere increases by an amount exceeding biotic sensitivity $\varepsilon_{\mathrm{b}}$, the biota 'does not know' whether the excessive carbon atoms appeared due to uncorrelated functioning of living organisms synthesizing and decomposing organic matter, or they came from the Earth's interior in the course of some physicochemical processes. The biota will compensate the environmental disturbance no matter what factors (biotic or abiotic) have led to the unfavorable change. Thus, once the biota uses the biotic regulation mechanism to cope with the huge fluxes of biochemical synthesis and decomposition, this means automatically that environmental disturbances introduced by all less powerful processes, including the physicochemical or anthropogenic ones, will be compensated as well.
Indeed, the available evidence suggests that the amount of dispersed organic carbon deposited in sediments during the Phanerozoic (last 700 million years) coincides in the order of magnitude $\left(10^{7} \mathrm{Gt} \mathrm{C}\right)$ with the amount of inorganic carbon that should have been accumulated in the atmosphere during the same period of time due to emission of inorganic carbon from the lithosphere (Budyko et al., 1987; Holmen, 1992). The biota removed the excessive carbon from the biosphere by converting it to chemically inactive organic matter and storing in sediments.

On the other hand, if there were no biotic regulation of environmental conditions, the environment would be destroyed by uncontrolled biotic processes four orders of magnitude more rapidly than by the physicochemical processes. (Processes of soil erosion, desertification, decline of biological productivity and water cycle are today's manifestations of such biota-mediated rapid environmental degradation (Turner, 2003).) Hence, both in the absence of biotic regulation as well as in the presence of it, the physicochemical processes of matter emission and deposition from the Earth's interior (as well as even less significant cosmic matter fluxes) appear to be of secondary importance in the consideration of environmental stability on a global scale.

We summarize that the existence of biotic regulation on Earth becomes evident from considering the magnitudes of the characteristic rates of environmental change under biotic impact $P^{ \pm}$, stores of environmental organic and inorganic components $M^{ \pm}$and the age of life $T$ or any other characteristic time of biological change, e.g., average time of species existence, which is of the order of several million years (Stanley, 1979). The needed value of $M^{ \pm}$cannot persist through time $T$ if exposed to an unregulated impact of power $P^{ \pm}$. The existence of biotic regulation follows from the observed relation

$\frac{M^{ \pm}}{P^{ \pm}} \ll T$

Under different physical conditions on Earth (e.g., at different values of solar luminosity) different biotas may appear most efficient in regulating their environment. This opens the way for evolutionary transitions. Once the biota changes in the course of biological evolution, its environmental preferences and, hence, the environment itself may undergo considerable 
changes remaining, however, under biotic control and within life-compatible limits at all times. A likely example of such a biotically controlled environmental change is the transition from reducing to oxidizing atmosphere about 2.5 billion years ago. Photosynthesizing plants appeared in the course of biological evolution and proved to be more efficient in creating and controlling their optimal environment than their evolutionary predecessors. The replacement of the old biota by the new one resulted in a major shift of environmental conditions.

\subsection{Physical instability of a climate with liquid hydrosphere}

There is an additional line of evidence that independently points to the existence of biotic regulation.

The contemporary life-compatible value of global mean surface temperature $\left(+15^{\circ} \mathrm{C}\right)$ is due to the non-zero value of the terrestrial greenhouse effect. As is well known, in the absence of the greenhouse effect, the global mean surface temperature would be $-18^{\circ} \mathrm{C}$ (Mitchell, 1989).

Greenhouse substances in the atmosphere absorb thermal photons emitted by the Earth and return some part of thermal radiation back to the surface, thus additionally heating it. The major greenhouse substance on Earth is water, which is present in the atmosphere in the form of vapor and cloudiness. Atmospheric water vapor is on average in equilibrium with liquid water contained in the global reservoir of the Earth's hydrosphere. The equilibrium amount of atmospheric water vapor strongly depends on surface temperature. In accordance with Clausius-Clapeyron equation, the amount of water vapor in the atmosphere doubles per each $10^{\circ} \mathrm{C}$ of surface temperature rise (Raval and Ramanathan, 1989). This leads to enhancement of the greenhouse effect, further heating of the surface, additional evaporation of water and so on. A climate with a liquid hydrosphere appears to be physically unstable with respect to spontaneous transitions either to a state of complete evaporation of the hydrosphere (with surface temperatures of about $+400^{\circ} \mathrm{C}$ ) or to a state of complete glaciation (with surface temperatures close to $-80^{\circ} \mathrm{C}$ ) (Gorshkov and Makarieva, 2002).

Characteristic times of such transitions could be quite short. If one assumes that a considerable amount of the incoming energy of solar radiation is spent on evaporation (currently about 20\% (Mitchell, 1989)), it is easy to calculate that the entire hydrosphere could completely evaporate in less than 10,000 years, elevating the surface temperature by several hundred degrees. However, the contemporary life on Earth would perish much earlier, as far as the photosynthetic tissues degrade already at temperatures approaching $60^{\circ} \mathrm{C}$.

The paleodata testify for a stable maintenance of the values of global mean surface temperatures within the interval $5-25^{\circ} \mathrm{C}$ during the last several hundred million years (Savin, 1977; Watts, 1982; Berggren and Van Couvering, 1984; Kutzbach, 1985), i.e., during the period for which the available data are likely to outweigh speculations. Over shorter time periods much smaller changes of surface temperature were recorded. In the absence of a physical mechanism that could ensure such a stability, these data can only be explained by accepting the existence of biotic regulation of the global water cycle and surface temperature. (Note that the problem of intrinsic physical instability of the Earth's climate should not be confused with a related and widely-discussed yet conceptually different problem of the runaway greenhouse effect (Ingersoll, 1969; Rasool and de Berg, 1979; Nakajima et al., 1992; Pujol and North, 2002). There the central question is whether a stationary solution to the climate problem is at all possible for Earth under various sets of initial conditions and external parameters like, e.g., solar luminosity. However, even if a stationary solution does exist, it can be unstable, and here lies the climate instability problem.)

Global biotic processes are powerful enough to control surface temperature (Sathyendranath et al., 1991; Gorshkov and Makarieva, 2002). Evapotranspiration processes in forest ecosystems control the water cycle on land (Shukla and Mintz, 1982; Gorshkov, 1995). In the ocean, the dominant parameter controlling absorption of the incident solar radiation is the concentration of photosynthetic pigment contained in phytoplankton cells. Where biological productivity is low and waters are transparent, the incident solar radiation propagates to larger depths. The oceanic surface remains cooler than it would be if all sunlight were absorbed at the surface (this is the case when the water turbidity is high). As soon as the sea surface becomes cooler, the equilibrium amount of water vapor in the atmosphere diminishes as well, reducing the local atmospheric greenhouse effect and, hence, further reducing 
sea surface temperature. Thus, to avoid the danger of overheating, it is sufficient for the oceanic biota to increase transparency of sea water. On the contrary, at higher latitudes where it is 'too' cold, a high turbidity of surface waters helps to generate the maximum greenhouse effect possible at a given insulation flux.

It is well known that the equatorial regions of the open ocean are least productive and hence most transparent (so-called oligotrophic waters), while the more productive and, hence, more turbid waters tend to the poles, despite the reverse trend in the availability of incident solar radiation and warmth (Russell-Hunter, 1970; Jerlov, 1976). The proposed mechanism of biotic regulation of surface temperature is able to explain the observed patterns of organization of marine ecosystems. (Note that the low availability of nutrients which is the apparent cause of low biologic productivity in oligotrophic waters is in itself a consequence of a particular spatial pattern of ecological community organization, when biological synthesis and decomposition are performed at different depths (Gorshkov et al., 2000, pp. 145-154).)

Modern climate change research is undoubtedly focused at the $\mathrm{CO}_{2}$ problem $\left(\mathrm{CO}_{2}\right.$ is the second important greenhouse gas on Earth): how will the surface temperature rise if the atmospheric $\mathrm{CO}_{2}$ concentration doubles, triples, etc. (see, e.g., IPCC, 1996). Implicitly, this means the same logic as in the case of no-waste technologies: no pollution $\leftrightarrow$ no environmental change; no anthropogenic $\mathrm{CO}_{2}$ emissions $\leftrightarrow$ no change of surface temperature; stabilized atmospheric $\mathrm{CO}_{2}$ concentration (at whatever level) $\leftrightarrow$ stabilized surface temperature. Interference of any other factors into this scheme is perceived as quite unexpected (Foley et al., 2003).

Apart from the $\mathrm{CO}_{2}$ problem, modern climatology focuses at studying various climatic cataclysms like, for example, the hypothetical complete glaciation of the planet several hundred million years ago (Hoffman et al., 1998) or some other catastrophic changes of climatic parameters (Alley et al., 2003). In other words, science is concerned about revealing and evaluating the geophysical factors that may cause undesirable climatic changes. Such studies are only justified if one believes that without such factors the suitable for life climate is stable by itself. Something extraordinary should then be identified to account for the observed climatic changes. Few climate change scientists would ask why surface temperature should remain in the life-compatible interval at all, given the powerful positive feedback between surface temperature and greenhouse effect conditioned by the presence of liquid hydrosphere.

The mainstream publication of Alley et al. (2003) devoted to abrupt climatic changes provides an instructive illustration for the situation in modern climatology. The authors' main point is that there are multiple, complex and interconnected factors that can bring about undesirable climatic changes. Stressing that serious research is needed to identify such factors, Alley et al. (2003) provide more than seventy references to publications of such kind. With respect to the state of Earth's climate in the absence of external forcing, Alley et al. (2003) remark laconically that "long-term stabilizing feedbacks have maintained Earth-surface conditions within the narrow liquid-water window conducive to life for about 4 billion years". One could expect that in the modern situation of global climate change the scientists would be interested in exploring the nature of such stabilizing feedbacks, to make sure that these feedbacks (that virtually keep our planet habitable) are not undermined in the course of the global anthropogenic transformation of the planet.

But, contrary to such expectations, modern science is apparently not concerned about mechanisms ensuring the intrinsic stability of the terrestrial climate. By way of explaining the stability issue, Alley et al. (2003) note very briefly that "short-term climate stability is provided by the increase in longwave radiation emitted by Earth as it warms, and reduction in emitted radiation as it cools". This is, however, a tautology rather than explanation. By definition, if a system is thermally stable, any increase of the system's temperature is accompanied by the increase of the rate at which heat is removed from the system. The problem with the Earth is to reveal those mechanisms that make our planet a thermally stable system. With respect to this problem, the attitude of Alley et al. (2003) is in agreement with that of Archer (2003) who notes that the overall stability of the climate record is not difficult to explain and that it is "generally attributed to a balance between degassing of $\mathrm{CO}_{2}$ from deep within Earth, and consumption of $\mathrm{CO}_{2}$ by weathering reactions at Earth's surface". (This statement is supported by referring to a single study (Walker et al., 1981) which ignores the positive water vapor 
feedback in the planetary greenhouse effect and, as the authors themselves admit, is speculative in terms of the quantitative results.) Such an attitude implies that, were there no $\mathrm{CO}_{2}$ and related external forcing like, e.g., carbon degassing, the climate stability on Earth would be self-evident. But what can stabilize a liquid hydrosphere preventing it from irreversible freezing or complete evaporation? This question receives little, if any, attention in the modern scientific literature.

\section{Life properties making biotic regulation possible}

The evidence presented in the previous section was meant to demonstrate that the dynamic equilibrium of the suitable for life environmental parameters on Earth appears as a delicate balance of powerful physical and biological processes controlled by the biota. Even if the direct anthropogenic pollution (e.g., $\mathrm{CO}_{2}$ emission) is stopped, the disintegration of the biotic regulation mechanism by over-exploiting natural ecosystems will render the environment unstable causing its rapid transition to life-incompatible states in terms of either surface temperature or environmental concentrations of life-important elements.

Importantly, the time-scale of the expected environmental decline is not of the order of billion years, as is often stated in discussions of various biota-environment negative feedback processes (Schwartzman and Volk, 1989; Schwartzman, 1999; Lenton and von Blohe, 2001), but hardly amounts to several centuries and is likely to be significantly shorter. Scientific assessment and conservation of the biotic regulation mechanism are therefore not of merely academic interest, but directly relevant to the acute environmental problems of today. We now discuss the fundamental properties of life organization that make biotic regulation possible.

\subsection{Ecological community}

In the contemporary biota synthesis and decomposition of organic matter are performed by different organisms that form ecological communities. Biotic regulation of the environment is a product of correlated functioning of all organisms in the ecological community. It is best illustrated on a concrete example.
Suppose that the concentration of atmospheric $\mathrm{CO}_{2}$ increases above the level optimal for the biota. To compensate this unfavorable change, the biota can, for example, increase the rate of biochemical synthesis $P^{+}$ as compared to the rate of decomposition $P^{-}$. The excessive atmospheric carbon will then be removed from the atmosphere and captured in the form of organic matter. Organic matter in the ecosystem is decomposed by various heterotrophic organisms. If their functioning is not correlated with functioning of those organisms that have produced the compensating change (e.g., plants), the appearing excessive organic matter can be immediately eaten up by the heterotrophs. The excessive carbon will then be released back into the atmosphere, zeroing the effect of biotic regulation. It follows that once there is an unfavorable environmental change, all organisms in the ecological community should modify their behavior in a correlated manner. In this particular example the heterotrophic organisms must ignore the excessive organic matter synthesized by autotrophic organisms and let it escape decomposition and leave the environment (e.g., by deposition in sediments).

\subsection{Orderliness of living systems: what makes the living matter alive}

Thus, for the biotic regulation to operate, interaction of species within ecological communities must be correlated, i.e., non-randomly organized or ordered. The information responsible for such correlated interaction of organisms is stored in the genomes of biological species.

In accordance with the second law of thermodynamics, all closed physical systems are disordered. Open physical systems can be ordered or 'self-organized' at the expense of external fluxes of free energy. The degree of orderliness of physical systems is therefore dictated by properties of the external energy fluxes. Quantitatively, the degree of orderliness can be estimated by the amount of information that can be stored in the system. That is, by the number of degrees of freedom (or memory cells) that are sufficient for description of the system.

One of the most common in the Earth's environment and best studied examples of physical selforganization is the turbulent flow of gases and liquids. At some critical value of the fluid stream velocity the 
flow no longer remains spatially uniform (laminar). There forms a pattern of non-random macroscopic structures (e.g., turbulent eddies) with definite spatial characteristics (Cross and Hohenberg, 1993). In other words, the system's space becomes structured, which is associated with information enrichment of the system. As a rule, the number of degrees of freedom of self-organized open physical systems grows with increasing supporting energy fluxes in accordance with a power law (Landau and Lifshitz, 1987).

The inanimate world consists of a small number of simplest chemical substances that cannot be used as molecular degrees of freedom in physical dynamic processes. Hence, all open physical systems on Earth are characterized by macroscopic memory cells, like eddies in a turbulent flow of liquid. By contrast, information of biological objects is stored in molecular memory cells in complex non-periodic DNA molecules. The volume density of information amount stored in physical dynamic processes observed in the environment appears therefore to be 24-25 orders of magnitude lower than the volume density of genetic information of living organisms (Gorshkov and Makarieva, 2001; Gorshkov et al., 2002).

Any physical dynamic system becomes disordered as soon as the external energy fluxes cease. As long as the fluxes persist, the system remains ordered. In this sense the word 'self-organization' is probably not the best one to describe orderliness of dynamic physical systems. By contrast, disorganization of individual living objects (death) is inevitable irrespective of the presence or absence of external energy fluxes (food). The environmental fluxes of free energy are virtually disordered as compared to living systems and cannot support the orderliness of the latter. Orderliness of living objects can only be maintained due to internal highly-ordered processes of biological nature.

This fact reveals the most remarkable property of life. Living matter is the matter which, first, features a level of orderliness incomparably higher than the surrounding environment and, second, supports its orderliness in a way unprecedented in the inanimate world-by competitive interaction. To sustain its orderliness, any type of living matter must be divided into a large number (population) of equivalent uniform objects. Genetic program of any individual object (or its offspring) inevitably undergoes decay prescribed by the second law of thermodynamics. As soon as the level of orderliness of any individual object diminishes by an amount discerned by the living matter, such an individual object is forced out from the population. Its place is occupied by a copy of a normal object retaining the initial level of orderliness. Such a competitive interaction allows to sustain the initial level of orderliness for infinite periods of time. This mechanism also makes possible further increase of orderliness (evolution), provided it is associated with higher competitiveness of the corresponding living objects.

In physical processes the external fluxes of free energy create orderliness and further support it. By contrast, life uses external energy not for direct support of its orderliness (which is impossible, as far as external energy fluxes are low-ordered as compared to life itself), but to compensate the energy expenses needed to fuel the processes of competitive interaction, reproduction and environmental control.

We stress that such a mechanism-forming a population of mutually uncorrelated uniform objects and switching competitive interaction among them-is the only way to sustain a high level of orderliness independent of the level of orderliness of environmental fluxes. Hence, any type of biological or ecological correlation (cell, multicellular organism, ecological community) may only persist if supported in the course of competitive interaction of the internally correlated objects. For example, correlation of organelles inside a cell or correlation of organs within a multicellular living body is maintained by competitive interaction of individual living organisms. Suppose life is represented by a single living individual, which produces one offspring throughout its life cycle. Whatever the initial level of correlation of its cells and organs, the inevitable decay of DNA molecules in the course of copying will lead to disintegration of functioning of the correlated units. For example, nothing prevents individual cells of the living body to evolve towards uncontrolled growth (cancer). This will cause death of the organism, which, in our hypothetical case, is equivalent to extinction of life itself.

\subsection{Impossibility of biotic regulation in a globally correlated biota (Gaia)}

Similarly, correlated functioning of organisms of different species within ecological communities can 
only be maintained in the course of competitive interaction of a large number of uniform ecological communities. Hence, the global biota cannot represent a single internally correlated ecological community. We illustrate it by two examples.

Example A: Suppose that at the initial moment of time the global biota is organized into a single internally correlated community where all species function in a correlated manner stabilizing the environment, like in the above example of atmospheric carbon. Genetic information written in the genomes of species ensures their correct correlated functioning in response to environmental disturbances. Once there appears an excess of atmospheric carbon, plants synthesize additional organic matter, while heterotrophs let it escape decomposition.

However, in the course of continuous copying of the genetic material of species during reproduction, there appear new genetic variants that change randomly the initial phenotypic properties of the corresponding organisms. For example, there may appear mutant bacteria that will choose to eat up all organic matter additionally synthesized by plants. Such "greedy" bacteria will act on their own, that is, in an uncorrelated manner with the other organisms. The community as a whole will be unable to control its environment and will perish together with the mutant bacteria as soon as the environmental conditions, left without biotic control, go beyond life-compatible limits.

Example B: The well known daisyworld of Gaia (Lovelock, 1982, 1995) represents another example of such a globally correlated ecological community prone to rapid self-disintegration in the course of genetic decay. The daisyworld is composed of white and black daisies and is able to regulate temperature of the planetary surface. This is achieved by programming the following correlated properties of the organisms: white daisies must reproduce better at higher temperatures, while black daisies must be more competitive at lower temperatures. As soon as the surface temperature rises, the white daisies enhance proliferation and partially replace the black ones. The planet's surface becomes lighter and returns more sunlight to space, so that the planet cools down.

Such a system is unprotected against genetic decay of those properties of species that ensure environmental stability. For example, nothing can prevent black daisies from becoming equally competitive in the higher temperature interval. If the surface temperature rises, the white daisies will then be unable to force out the black ones, thus making the biotic control of surface temperature impossible (Robertson and Robinson, 1998). Alternatively, white daisies could mutate to some darker color. In such a case, even if the lighter daisies force out the darker ones during a temperature rise, the resulting change in reflectance of the planetary surface can appear insufficient to fully compensate the unfavorable changes of surface temperature. More generally, it is clear that the initial correlation of properties of white and black daisies can disintegrate in hundreds of ways.

Namely this property of Gaia and the daisyworld has been repeatedly criticized (Doolittle, 1981; Dawkins, 1982; Baerlocher, 1990; Saunders, 1994; Robertson and Robinson, 1998; Staley, 2002) by questioning the possibility of such a system to originate and persist in the course of biological evolution. With regard to the correlated system "black-and-white-daisies", an independent evolution of any of its components is equivalent to decay and disintegration.

Such scenarios can only be avoided if the global biota is composed of a large number of independently functioning uniform ecological communities. The universal way of maintaining the orderliness of living objects-competitive interaction between uniform objects-will support internal correlation of ecological communities preventing it from decay.

In Example A, as soon as in any local ecological community there appear the mutant bacteria preventing their community from efficient control of environmental conditions, the local environment of such a community will start deteriorating. As soon as the degree of deterioration becomes significant (i.e., the relative environmental change exceeds biotic sensitivity $\varepsilon_{\mathrm{b}}$ ), all inhabitants of the local ecological community, including the mutant bacteria, will loose competitively to their conspecifics from the neighboring local ecological communities. (The latter continue to perform efficient environmental control and enjoy the optimal environment.) As a result, the local area initially occupied by the decay community will be re-colonized. A new normal local ecological community will be formed from normal organisms with correlated behavior and initial high level of orderliness.

In Example B, we can imagine the daisyworld consisting of separate local ecological communities 
(e.g., flowerbeds), each controlling its local environment. As soon as in any of them there appears a defective daisy, all other daisies in the respective local flowerbed find themselves in an uncontrolled (or less efficiently controlled) and, hence, less hospitable environment. If the destabilizing impact of the defective daisy causes a biotically significant environmental deterioration (i.e., the relative change of local temperature exceeds biotic sensitivity $\varepsilon_{\mathrm{b}}$ ), all daisies in this flowerbed will lose competitiveness as compared to daisies from the adjacent normal flowerbeds that retain optimal environmental conditions. Normal daisies from the neighboring flowerbeds will start invading the decay flowerbed and force out its defective inhabitants. In the end, as in the previous case, a new normal flowerbed is formed, which is again fully capable of environmental control.

\subsection{Impossibility of technological environmental control}

As a concluding remark to the discussion of the level of order in the living matter, it is worthy to note the following. In a living cell practically all molecules participate in non-random biochemical reactions supporting life. The amount of information processed by one living cell per unit time coincides in the order of magnitude with information flux processed by modern personal computer (Gorshkov, 1996; Gorshkov et al., 2002). The biota comprises about $10^{29}$ living cells (Gorshkov, 1995; Whitman et al., 1998). In the modern civilization the number of personal computers cannot significantly exceed the number of people, which is of the order of $10^{9}$. Hence, there is a 20 orders of magnitude's gap between information fluxes available to the natural biota and civilization. As such a gap can never be bridged, the natural biotic regulation of the environment cannot be substituted by technology.

\section{Mechanism of biotic regulation}

\subsection{Locally and globally regulated biogens}

In the previous section, we came to the conclusion that the biotic regulation mechanism can only escape genetic decay, if there is a sufficiently large population of uniform local ecological communities each of them benefiting from regulating its local environment. We will now pursue the question of how regulation of global environmental conditions can be realized in such a biosphere. Indeed, it might seem at a first glance that as far as many local ecological communities share approximately the same global environmental conditions like surface temperature or atmospheric $\mathrm{CO}_{2}$ concentration, there is no competitive advantage of those communities that regulate such conditions over those that do not (Doolittle, 1981; Dawkins, 1982; Staley, 2002). In such a case, the competitive interaction would be unable to prevent the mechanism of biotic regulation from decay.

Chemical elements involved into the biochemical cycle are continuously traveling from inorganic substances to organic ones, and back. It is natural therefore to call such life-important chemical elements (usually referred to as nutrients in ecology) as organic and inorganic biogens, dependent on the nature of the substance they are present in, e.g., organic and inorganic carbon, nitrogen, etc.

Local concentrations of biogens can change both due to the local biotic fluxes of synthesis and decomposition of organic matter, as well as due to the local fluxes of physical mixing that work to equate the biogen concentrations between the adjacent areas. As far as the processes of synthesis and decomposition are correlated via biotic regulation, the power of biotic fluxes can be characterized by a single value $P=$ $P^{+} \approx P^{-}$(dimension mole $\mathrm{X} \mathrm{m}^{-2} \mathrm{~s}^{-1}$, where $\mathrm{X}$ is the considered biogen).

Local physical fluxes of biogens, $F$, are governed by diffusion processes. They are proportional to the concentration gradient $\Delta[\mathrm{X}], F=D \Delta[\mathrm{X}]$, where $D$ is the coefficient of molecular or eddy diffusion, [X] is the concentration of biogen $\mathrm{X}$. In the approximation of a linear gradient the net flux $F$ can be written as

$$
\begin{aligned}
& F=F_{\text {in }}-F_{\text {out }}, \quad F_{\text {in }}=\frac{D}{L}[\mathrm{X}]_{\text {out }}, \\
& F_{\text {out }}=\frac{D}{L}[\mathrm{X}]_{\text {in }},
\end{aligned}
$$

where $[X]_{\text {in }}$ and $[X]_{\text {out }}$ are concentrations of biogen $X$ within the considered local area of life functioning and outside it, respectively; $F_{\text {in }}$ and $F_{\text {out }}$ are the incoming and outcoming gross physical fluxes of biogen $\mathrm{X}$ with respect to the considered area; $L$ is the ecologically relevant linear size of the considered area (e.g., height 
of vegetation cover, soil depth, depth of euphotic layer in aquatic ecosystems, etc.).

When the gross physical fluxes are no more powerful than biotic productivity

$F_{\text {in }} \leq P, \quad F_{\text {out }} \leq P$,

the local biota is able to maintain any value of concentration $[\mathrm{X}]_{\text {in }}$ of biogen $\mathrm{X}$ within the considered local area, no matter how large the difference between $[\mathrm{X}]_{\text {in }}$ and $[\mathrm{X}]_{\text {out }}$. In such a situation, it is natural to call biogen $\mathrm{X}$ locally regulated. Among these one can name practically all organic biogens (in live and dead biomass, detritus and humus of all soil horizons, dissolved organic matter of aquatic ecosystems), as well as all inorganic biogens of soil and aquatic ecosystems, including $\mathrm{CO}_{2}$ and $\mathrm{O}_{2}$.

For example, for inorganic soil phosphorus, $\mathrm{X} \equiv$ $\mathrm{P}$, we have $[\mathrm{P}]_{\text {in }} \leq 10 \mathrm{~mol} \mathrm{P} \mathrm{m}^{-3}$ (Fedorov and Gilmanov, 1980). Phosphorus leaves the ecosystem in the process of molecular diffusion with $D \leq$ $10^{-2} \mathrm{~m}^{2}$ per year (Broecker and Peng, 1974). Taking production of phosphorus by terrestrial biota to be about $P \sim 0.3 \mathrm{~mol} \mathrm{P} \mathrm{m}^{-2}$ per year (Whittaker and Likens, 1975) and thickness of soil layer of about $L \sim$ $0.3 \mathrm{~m}$, we obtain that the gross flux of phosphorus out of the ecosystem does not exceed the biological productivity, $F_{\text {out }} \sim[\mathrm{P}]_{\text {in }} D / L \sim P$.

When the gross physical fluxes significantly exceed the biotic productivity, $F_{\text {in }} \approx F_{\text {out }} \gg P$, the local biota is unable to maintain a large relative difference in concentrations of biogen $\mathrm{X}$ within and outside the area of life functioning. The maximum relative difference of concentrations $\varepsilon \equiv\left([\mathrm{X}]_{\text {in }}-[\mathrm{X}]_{\text {out }}\right) /[\mathrm{X}]_{\text {in }}$ the local biota is powerful enough to maintain is found from the condition that the net physical flux caused by this difference is equal in power to biotic productivity:

$P=F=\left([\mathrm{X}]_{\text {in }}-[\mathrm{X}]_{\text {out }}\right) \frac{D}{L}=\varepsilon F_{\text {out }}$,

$\varepsilon=\frac{P}{F_{\text {out }}}, \quad \varepsilon \ll 1$.

Any larger difference would be immediately destroyed by the powerful physical mixing.

Consider now a situation when due to functioning of some destabilizing processes the concentration of an inorganic biogen [X] in the global environment (e.g., in the atmosphere) has significantly exceeded the biotic optimum, $\left([\mathrm{X}]_{\text {out }}-[\mathrm{X}]_{\mathrm{opt}}\right) /[\mathrm{X}]_{\mathrm{opt}} \gg \varepsilon_{\mathrm{b}}$.
If the relative difference $\varepsilon$ between $[\mathrm{X}]_{\text {in }}$ and $[\mathrm{X}]_{\text {out }}$ maintained by the biota, see (4) and (5), exceeds the biotic sensitivity $\varepsilon_{\mathrm{b}}, \varepsilon \geq \varepsilon_{\mathrm{b}}$, all local ecological communities that perform such a small but significant change of $[X]_{\text {in }}$ towards $[X]_{\text {opt }}$ will find themselves in a slightly but significantly better environment than those not performing such a change. To remain equally competitive, all local ecological communities must therefore maintain one and the same difference $\Delta[\mathrm{X}]$, in terms of both sign and magnitude. Such a difference can be maintained due to conversion of the incoming inorganic biogen into inactive organic form.

If the total area occupied by such communities is large, there will arise a globally significant physical flux of biogen $\mathrm{X}$ into the considered area of life functioning (or outwards, if $[\mathrm{X}]_{\text {out }}<[\mathrm{X}]_{\mathrm{opt}}$ ). Such a flux continues until the concentrations outside the ecological community $[\mathrm{X}]_{\text {out }}$ and inside it $[\mathrm{X}]_{\text {in }}$ become equal to each other coinciding with the optimum $[\mathrm{X}]_{\mathrm{opt}}$ to an accuracy of $\varepsilon_{\mathrm{b}}$. It is natural to call biogens for which $P \ll F_{\text {in }} \approx F_{\text {out }}$ but $\varepsilon \geq \varepsilon_{\mathrm{b}}$ as globally regulated (Gorshkov, 1986). An example of biotic control of globally regulated biogens is schematically shown in Fig. 1.

If the condition $\varepsilon \geq \varepsilon_{\mathrm{b}}$ is not fulfilled, the improvement of the environment by the biotic processes appears to be too small for the biota to feel it. In such a case, those local ecological communities that perform the stabilizing change and those that do not will enjoy equal environmental conditions. Biotic regulation of such biogens is impossible. Such biogens might be called biotically unregulated. Concentrations of biotically unregulated biogens are free to change in unfavorable directions ultimately reaching life-incompatible values. This points to the fact that on a global scale there are no such biogens, i.e., no life-important chemical elements escaping biotic control.

Biotically unregulated biogens may only exist locally or within limited time periods. For example, biogens unregulated by the local biota can be found in rapid water streams and during storms and hurricanes. Then the values of gross physical fluxes $F_{\text {in }}$ and $F_{\text {out }}$ are too large, while the corresponding values of $\varepsilon$ are too small, $\varepsilon \ll \varepsilon_{\mathrm{b}}$, see (5). Unregulated biogens can be also observed seasonally, when biotic productivity is naturally suppressed; after fires or cutting, when the biota is locally destroyed; and in deserts, where biota 


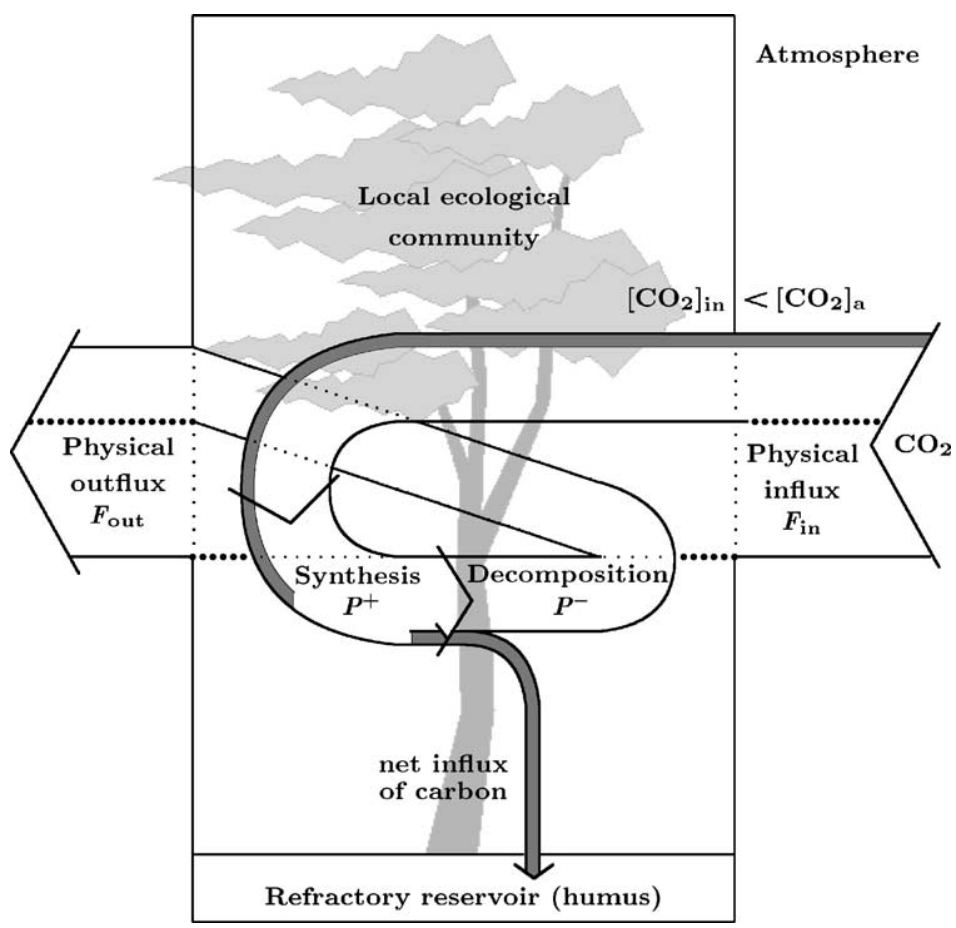

Fig. 1. Control of globally regulated biogens by the local ecological community on the example of atmospheric $\mathrm{CO}_{2}$ in a situation when the atmospheric $\mathrm{CO}_{2}$ concentration is larger than the community's optimum, $\left[\mathrm{CO}_{2}\right]_{\text {out }} \equiv\left[\mathrm{CO}_{2}\right]_{\mathrm{a}}>\left[\mathrm{CO}_{2}\right]_{\text {opt }}$. Large arrows: gross fluxes of physical mixing (wind) that work to equate ambient $\mathrm{CO}_{2}$ concentration in the adjacent ecosystem units. Medium arrows: Fluxes of biochemical synthesis and decomposition that work to decrease the local concentration $\left[\mathrm{CO}_{2}\right]_{\text {in }}$ driving it towards the optimum. The smallest arrow (darkened): the resulting net influx of organic carbon deposition in a refractory reservoir.

is virtually absent. In all such cases the biological productivity $P$ is low and, according to $(5), \varepsilon \ll \varepsilon_{\mathrm{b}}$.

\subsection{Examples of globally regulated and unregulated biogens: atmospheric carbon and oxygen}

Vertical physical transport of atmospheric carbon in forests is characterized by an eddy diffusion coefficient, which depends on wind speed and is, on average, of the order of $D \leq 10^{7} \mathrm{~m}^{2}$ per year (Fedorov and Gilmanov, 1980). The average vertical size of forest ecosystems is of the order of $L \sim 30 \mathrm{~m}$. Maximum productivity of forest communities is about $P^{+} \sim$ $10^{2} \mathrm{~mol} \mathrm{C} \mathrm{m}^{2}$ per year (Whittaker and Likens, 1975). The global average atmospheric carbon concentration is equal to $\left[\mathrm{CO}_{2}\right]_{\mathrm{a}} \sim 10^{-2} \mathrm{~mol} \mathrm{C} \mathrm{m}{ }^{-3}$ (Watts, 1982). This gives $\varepsilon_{\left[\mathrm{CO}_{2}\right]_{\mathrm{a}}} \sim P^{+} L /\left(D\left[\mathrm{CO}_{2}\right]_{\mathrm{a}}\right) \sim 0.03$, i.e., about $3 \%$. Direct measurements confirm that the concentration of $\mathrm{CO}_{2}$ in the internal atmospheres of tree canopies, $\left[\mathrm{CO}_{2}\right]_{\text {in }}$, can indeed differ from that in the surrounding atmosphere, $\left[\mathrm{CO}_{2}\right]_{\text {out }} \equiv\left[\mathrm{CO}_{2}\right]_{\mathrm{a}} \sim$ $\left[\mathrm{CO}_{2}\right]_{\text {in }}$, by several per cent (Kobak, 1988). Seasonal fluctuations of atmospheric $\mathrm{CO}_{2}$ concentration do not exceed 3\% (Gorshkov and Sherman, 1986). As far as during the last 10,000 years global $\mathrm{CO}_{2}$ concentrations remained practically without noticeable changes (Siegenthaler and Sarmiento, 1993), it is unlikely that the biotic sensitivity $\varepsilon_{\mathrm{b}}$ with respect to atmospheric $\mathrm{CO}_{2}$ exceeds several per cent, $\varepsilon_{\mathrm{b}} \sim 10^{-2}$. (Otherwise $\mathrm{CO}_{2}$ concentrations would fluctuate by at least tens of per cent over time periods of the order of the turnover time for atmospheric carbon.) Thus, the condition $\varepsilon \geq \varepsilon_{\mathrm{b}}$ is fulfilled for atmospheric $\mathrm{CO}_{2}$ and it is globally regulated by the natural biota.

By contrast, atmospheric oxygen appears to be biotically unregulated with respect to the terrestrial above-ground biota. Indeed, atmospheric oxygen is transported by the same physical fluxes as atmospheric 
$\mathrm{CO}_{2}$. Functioning of the biota ensures similar absolute differences in concentrations of $\mathrm{CO}_{2}$ and $\mathrm{O}_{2}$ (due to close to unity stoichiometric $\mathrm{C} / \mathrm{O}$ ratios in biochemical reactions). However, as far as concentration of atmospheric oxygen $\left[\mathrm{O}_{2}\right]_{\mathrm{a}}$ is four orders of magnitude higher than that of $\mathrm{CO}_{2}$, the relative difference $\varepsilon$ in oxygen concentrations that can be maintained by the biota appears to be four orders of magnitude lower than that for the atmospheric $\mathrm{CO}_{2}$, i.e., of the order of $\varepsilon_{\left[\mathrm{O}_{2}\right]_{\mathrm{a}}} \sim 10^{-6}$. Whatever the biotic sensitivity $\varepsilon_{\mathrm{b}}$ of the above-ground terrestrial biota with respect to atmospheric oxygen, it is unlikely that it is lower than $10^{-6}$. Thus, the above-ground terrestrial biota is unable to control atmospheric oxygen, as far as for atmospheric oxygen $\varepsilon_{\left[\mathrm{O}_{2}\right]_{\mathrm{a}}} \ll \varepsilon_{\mathrm{b}}$.

However, in aquatic ecosystems, bogs and in wet soils oxygen appears to be locally regulated. The saturated concentration of dissolved oxygen $\left[\mathrm{O}_{2}\right]_{\mathrm{d}}$ is 40 times lower than in the atmosphere (Levitus, 1982), while diffusion coefficients $D$ in water are four orders of magnitude lower than in the air (Broecker et al., 1985). The relative difference in local concentrations of the dissolved oxygen that can be maintained by the aquatic or soil biota is therefore nearly six orders of magnitude higher than the above-ground terrestrial biota can afford and is of the order of unity, $\varepsilon_{\left[\mathrm{O}_{2}\right]_{\mathrm{d}}} \sim$ 1. Assuming that the biotic sensitivity with respect to oxygen is of the same order of magnitude as the biotic sensitivity with respect to atmospheric $\mathrm{CO}_{2}, \varepsilon_{\mathrm{b}} \sim$ $10^{-2}$, we have $\varepsilon_{\left[\mathrm{O}_{2}\right]_{\mathrm{d}}} \gg \varepsilon_{\mathrm{b}}$.

Thus, in the ocean, in aquatic ecosystems on land and in soil the concentration of dissolved $\mathrm{O}_{2}$ remains under full biotic control and can be maintained at any level optimal for the local biota. Atmospheric oxygen is in physical equilibrium with the dissolved oxygen of the ocean. The value of atmospheric oxygen concentration is prescribed by physical factors that cannot be affected by the above-ground terrestrial biota. The possibility of existence of the above-ground biota at a given value of atmospheric oxygen concentration is therefore likely to be of accidental nature, similar to the possibility of life existence at a given value of terrestrial gravity, flux of solar radiation and other environmental parameters that cannot be changed by the biota. If it proved biochemically impossible for life to exist at the modern values of atmospheric oxygen concentration, then life would be unable to colonize the land after transition from reducing to oxidizing atmosphere and would have to remain in the aquatic environments.

\subsection{Local ecological communities, large animals and forest succession}

As discussed above, the biota should be composed of a large number of uniform local ecological communities capable of regulating their local environment. In other words, the biota should be structured, and its uniform structural units should feature a finite size. The space scale of such structural units of the biota-we suggest calling them ecosystem units-should be defined as the area within which the biochemical cycle of synthesis and decomposition of locally regulated biogens is closed to an accuracy of biotic sensitivity $\varepsilon_{\mathrm{b}}$. The size of such an area can be determined experimentally, for example with use of radioactive labels (see, e.g., the study of Lerat et al. (2002)). Living organisms inhabiting one and the same ecosystem unit compose local ecological community.

As immediately suggested by visual inspection of the spatial organization of forests - the most extensive natural ecosystems on land-such a structural unit of the terrestrial biota is likely to be a single tree together with the attached under-canopy flora and fauna (bacteria, fungi, small invertebrates). These organisms are responsible for consumption of more than $90 \%$ of primary productivity (Odum, 1971; Makarieva et al., in review) and, together with trees, fully control the ecosystem's energetics. There is a tight correlation between the root-mycorrhiza systems of dominant trees and under-canopy vegetation, which facilitates mutually beneficial sharing of both inorganic and organic nutrients among the dominant tree and the smaller under-canopy plants (Lerat et al., 2002). Dominant plants create and maintain the chemical composition of soil and dictate its spatial organization (Hook et al., 1991; Rhoades, 1997; Døckersmith et al., 1999). Spatial distribution of the smallest heterotrophs, bacteria and mycorrhizal fungi, was also shown to be autocorrelated around individual trees (Pennanen et al., 1999). This allows the tree to close biochemical cycles on a local scale, thus supporting soil fertility (Heinonsalo et al., 2001). It is natural therefore to consider an individual tree, the associated under-canopy vegetation, the local heterotrophic biota and their local environment as an elementary ecosystem unit of the forest 


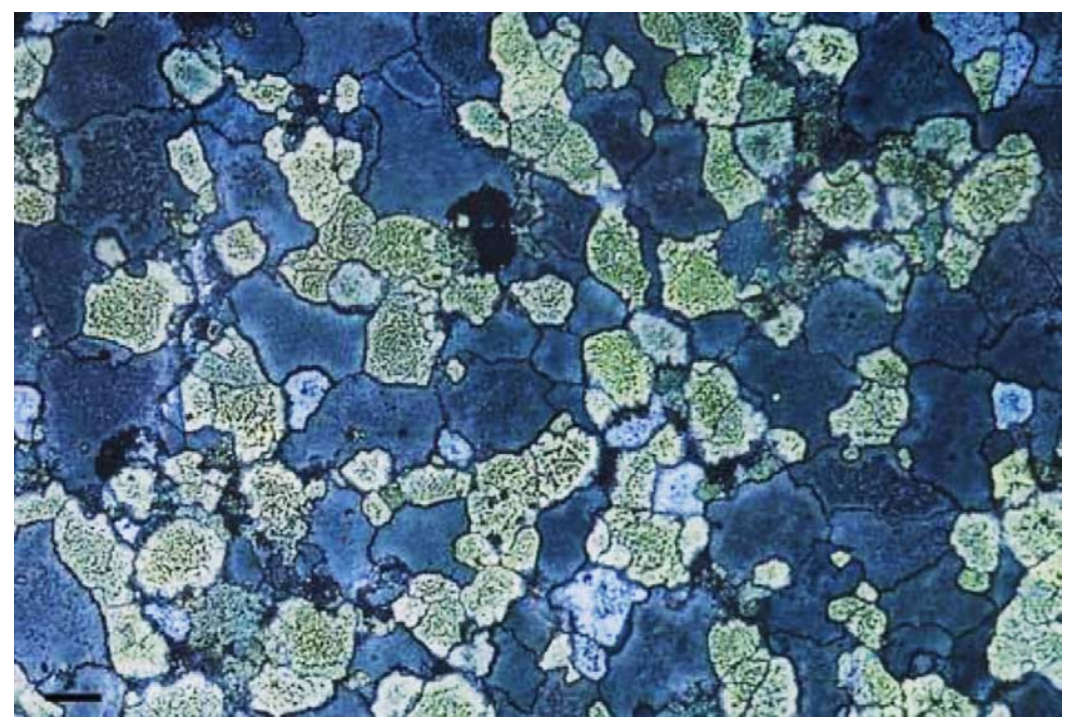

Fig. 2. Ecosystem units on the example of epilithic lichens of Rhizocurpon sp. (light) and Lecidea sp. (dark) forming a continuous cover on a large piece of rock. The visible borders delimitate the adjacent ecosystem units. The black bar in the left-hand lower corner denotes horizontal linear scale of $1 \mathrm{~cm}$.

ecosystem. Hence, the space scale of ecosystem units in forests is likely to be equal to the projection area of individual trees, which is of the order of $10-100 \mathrm{~m}^{2}$.

In the simplest ecosystems found on Earth-epilithic lichens that consist of one algae and one fungi species (Farrar, 1976) - the boundaries of adjacent ecosystem units are visible (Fig. 2). In these ecosystems, the size of ecosystem units does not presumably exceed several square centimeters, although more precise determination can only be made by analysis of radioactive labels. Radioactive labels are expected to circulate within ecosystem units not crossing their boundaries.

Individual feeding territories and home ranges of larger mobile animals (e.g., flying insects, mammals, birds, reptiles, etc.) considerably exceed the size of a single ecosystem unit. The share of energy consumption allocated to such animals in natural undisturbed ecosystems does not exceed several per cent of the ecosystems' primary productivity (Bray, 1964; Wiegert and Owen, 1971; Grodzinski, 1971; Humphreys, 1979; Gorshkov, 1981; Makarieva et al., in review). Mobile animals can be therefore regarded as a certain component of the environment, which is shared by different local ecological communities and can be regulated by them in the same manner as the concentrations of globally regulated biogens. If the population density of a given species deviates from the optimum, local ecological communities may react to that change by attenuating environmental conditions favorable for that species. For example, if the population density of a large herbivorous mammal becomes lower than the optimum, the local ecological community may accelerate production of edible plant parts. All local ecological communities proceed with such an impact until the population density of the considered species returns to the optimum value.

Large animals are encountered in the overwhelming majority of ecosystems. This indicates that their presence contributes to the competitive capacity of individual local ecological communities. The contribution of large animals to the biotic regulation process can be clarified on the example of forest succession.

Consider an old-growth natural spruce forest affected by a large-scale disturbance like fire, windfall, volcanic eruption or (today) clear-cutting. Such a disturbance exterminates all local ecological communities (trees and the associated biota) on the affected area. Moreover, the local environmental conditions deteriorate to such a significant degree that the organisms from the adjacent ecosystem units that remain unaffected by the disturbance cannot immediately colonize the perturbed area. Hence, the deteriorated 
environment of the perturbed area remains without biotic control and is allowed to degrade further. Sooner or later, the whole of the terrestrial biota becomes extinct, because any local territory is one day to be destroyed by one or another large-scale disturbance.

However, life has invented a peculiar mechanism to counteract such large-scale disturbances. The initial undisturbed ecological community (which is called climax community and can be exemplified by spruce Picea sp. and the associated biota in boreal forest ecosystems) supports existence of the so-called pioneer species (e.g., fireweed Chamaenerium angustifolium, shorthear Calamagrostis spp., clover Trifolium spp., etc.). In the absence of large-scale disturbances the population density of pioneer species is kept at a low level. However, namely the pioneer species are able to colonize the deteriorated environment immediately after the large-scale disturbance. The ecological function of the pioneer species is to restore the perturbed environment to its initial state making it suitable again for the dominant species of the initial undisturbed communities. After that is done, organisms belonging to the initial climax community re-colonize the repaired area and suppress population density of pioneer species down to its initial low level. Bearing in mind their ecological and environmental function, it is natural to call the pioneer species and species of the later successional stages as species-repairers.

There is a fundamental difference between speciesrepairers and species dominating the initial climax community. In the absence of external disturbances, climax communities are able to keep their own optimal environment stable for infinitely long periods of time. By contrast, species-repairers are unable to support their favorable (i.e., disturbed) environment where they feature highest population numbers. Instead, species-repairers rapidly change such an environment in a direction that is unfavorable for themselves but favorable for species of the climax community. If this were not the case, species-repairers could never be forced out by the climax species.

This remarkable property of species-repairers makes them vulnerable to extinction, if the relevant large-scale disturbance does not occur for a long time. Left without species-repairers, the climax communities are unable to cope with such a large-scale disturbance when it ultimately occurs. Thus, the climax communities must have a special mechanism supporting stable (although low) population numbers of species-repairers even in the absence of external environmental disturbances. One way of achieving this is to give home to large animals. By consuming plant biomass, trampling vegetation, digging in the ground, etc., large animals introduce considerable disturbances of the local environment (e.g., clearings ('bais') made by elephants in tropical forests). By doing so, large animals create environmental conditions favorable for the species-repairers and relax their dependence on irregular external disturbances.

The process of succession, which culminates in the restoration of the initial undisturbed environment, is a highly-ordered non-random process based on information written in the genomes of participating species. Ecological and environmental order that emerges in the course of succession (e.g., the non-random interactions between organisms or the specific properties of the restored environment) is therefore a manifestation of already existing genetic information. This information remains practically unchanged for time periods of the order of several million years (mean time of species existence, see the discussion below). Unlike sometimes stated, environmental change cannot lead to 'self-organization' of a new type of a self-sustainable ecological community.

We note finally that most work on biotic regulation of global environmental parameters, including the biotic control of water cycle and atmospheric carbon concentration, is performed by climax communities rather than by communities at various successional stages. During succession, the most part of biotic power is likely to be spent on self-recovery and restoration of local environmental conditions.

\section{Discussion: the need to revise the scientific paradigms}

In this paper, we have invited the reader to look at the phenomenon of life from a different perspective, which is in many ways at odds with the frameworks of thought adopted in the modern biological, ecological and environmental science.

Biotic regulation of the environment is a highly ordered process, which is based on the genetic information of species. As discussed in Section 3, this information is prevented from decay in the course of 
competitive interaction among conspecific organisms, as well as among higher-rank correlated associations of organisms, up to local ecological communities. Whenever the environment considerably deviates from the optimum, the genetically programmed behavior of species ensures biotic processes that fully compensate the unfavorable change. In other words, the genetic program of species constitutes the informational basis for the compensatory environmental processes initiated by the biota when challenged by an environmental change. As such, the genetic information of species cannot change in response to environmental perturbations. This means that species do not adapt genetically to a changing environment.

The available paleodata provide an independent testimony that such an adaptation does not take place. The overwhelming majority of paleospecies demonstrate strict discreteness (Stanley, 1979; Gould and Eldridge, 1993; Jackson, 1990, 1994). Species that succeed each other in the paleorecord do not smoothly grade into each other (as they would do if continuously adapting to the changing environment), but appear abruptly as discrete morphological and genetic entities and further persist virtually unchanged for millions of years. By far, most of the extant species also demonstrate strict discreteness.

The idea that life adapts genetically to environmental change is among the central paradigms in the biological theory. It originally comes from considering the process of artificial selection. Man selects animals and plants for particular properties (e.g., high rate of milk production in cattle). The new breeds created appear to be genetically different from the wild type. This allows to assume that if the natural environment changes in such a manner that cows producing more milk become advantageous, a similar shift of the genetic composition of species will occur in nature as well. That a new breed can be created very quickly works to convince one that genetic adaptation is a routine process frequently encountered in nature.

In the optimal environment controlled by natural biota, the most competitive organisms of a given species are those performing the needed correlated interaction with all the other organisms of the local ecological community. The amount of genetic polymorphism maintained in the population is dictated by the limited value of sensitivity of natural competitive interaction (Makarieva, 2001). If wild organisms are extracted from their habitats and placed under artificial conditions never encountered in their natural environment, those highly-ordered properties that imparted them high competitiveness in nature will appear useless. The genetic information responsible for these properties will start to decay.

Such a decay will be manifested as an increase in genetic polymorphism of the population and appearance of organisms with various defective properties not encountered in the wild type (Gorshkov and Makarieva, 1997). Some of these properties may accidentally prove useful for man. However, the organism-environment relationship in such defective organisms is fundamentally different from that in their wild relatives and can be in no way considered as an adaptation. This is because unlike their wild type conspecifics, artificially selected organisms are unable to control their environment. Any external disturbance destroying their unnatural environment results in their extinction. Hence, the fact that in artificial or anthropogenically perturbed environments there sometimes appear organisms with phenotypic properties absent in the wild type is not a proof of genetic adaptation to a changed environment.

It is remarkable that artificial selection may only operate with individual species. It has never produced a new 'breed' of ecological community, which would display the same environmental homeostasis as do natural ecological communities. This cannot be surprising if one accepts that artificial selection operates with products of decay of the genetic programs of natural species. All artificially maintained ecological systems (pastures, croplands, etc.) rapidly degrade together with their environment. Admitting the failure of the long-standing attempts to technologically maintain the stability of artificial ecological systems (see also discussion in Section 3.4), modern agricultural science recommends exploitation regimes mimicking the natural conditions as closely as possible as the only remedy able to mitigate environmental degradation (Altieri, 1991; Wardle et al., 1995; Yeates et al., 1997; Bardgett and McAlister, 1999).

The genetic adaptation paradigm would be rapidly dismissed or never arose at all, if the central question of natural science would be 'Why does the suitable for man environment persist through time?' However, as we noted in the Introduction, for the most part of human history the problem of environmental 
degradation has been non-existing. There has been no motivation to explore the foundations of environmental stability. Today such a motivation is very clear. It is reasonable therefore to undertake a revision of the old paradigms, bearing in mind that their implications can be dangerously misleading.

Indeed, the genetic adaptation paradigm implicitly invites to adapt to the global environmental change rather than to try to stop it. Adaptation to the changing world is presented like a reliable recipe that allowed life to persist through billions of years. The genetic adaptation paradigm associates no harm with further cultivation of the remaining natural biota of Earth. Neither does it give any logical grounds for global-scale conservation of natural species and their habitats. The extinction of natural species under anthropogenic pressure can be viewed as a part of the natural evolutionary processes where the weakest and least adapted are destined to perish. Referring to the ubiquitous spread and huge population numbers of humans on Earth, the genetic adaptation paradigm depicts Homo sapiens as the most successful species.

Through practical implications of such an approach, modern science can do a fatal disservice to the humanity. As we discussed in Section 1, life has not adapted to the changing environment, but kept the environment under control at all times-otherwise it is impossible to explain the persistence of life over any substantial periods of time. Humans, although effectively forcing out other species from their natural habitats, are inferior to species of natural ecological communities in being unable to sustain environmental conditions favorable for themselves. If Homo sapiens continues this 'successful adaptation', the natural ecosystems of Earth will be completely destroyed. As soon as this happens, the humanity will have nothing to do but wait until the uncontrolled environment degrades to a state unfit for life, with no power to prevent such an undesirable outcome (Section 3.4).

\section{Conclusions}

Three major statements can summarize the content of this paper. First, the suitable for life environment is not sustainable 'by itself'; it is maintained by biotic regulation and rapidly (on a time scale of hundreds of years) degrades to a state unfit for life as soon as the latter ceases. Second, the ability of environmental regulation is a property of internally correlated natural ecological communities of species undisturbed by anthropogenic activities. Third, the life-compatible environment on Earth cannot be stabilized by artificial ecological systems or by technological means.

For the most part of its history, the humanity has been dramatically underestimating the natural biota of Earth, considering it in primitive consumer's terms as a source of food, structural materials, aesthetic pleasure or, lately, as a genetic resource. Such an attitude-mirrored in, and fostered by the existing scientific paradigms - has determined the world-wide spread of exploitative policies with respect to the natural biota. However, as is now becoming progressively more evident, natural biota represents a unique ultra-complex mechanism responsible for maintenance of Earth's habitability. If the long-term sustainability of favorable environmental conditions is a priority for modern humanity, the natural biotic regulation mechanism must be allowed to continue to operate on Earth.

It is therefore important to quantitatively assess the stabilizing impact of natural ecosystems. This will make it possible to determine the necessary and sufficient global area that must be exempted from anthropogenic activities and let be occupied by natural ecosystems, so that the latter have power enough to keep the global environment in a stable, life-compatible state. This scientific task emerges as the major challenge for modern ecological science.

\section{References}

Alley, R.B., Marotzke, J., Nordhaus, W.D., Overpeck, J.T., Peteet, D.M., Pielke Jr., R.A., Pierrehumbert, R.T., Rhines, P.B., Stocker, T.F., Talley, L.D., Wallace, J.M., 2003. Abrupt climate change. Science 299, 2005-2010.

Altieri, M.G., 1991. How can we best use biodiversity in agroecosystems? Outlook Agric. 20, 15-23.

Archer, D., 2003. Who threw that snowball? Science 302, 791-792.

Baerlocher, F., 1990. The Gaia hypothesis: a fruitful fallacy? Experimentia 46, 232-238.

Bardgett, R.D., McAlister, E., 1999. The measurement of soil fungal:bacterial biomass ratios as an indicator of ecosystem self-regulation in temperate meadow grasslands. Biol. Fertil. Soils 29, 282-290.

Berggren, W.A., Van Couvering, J.A. (Eds.), 1984. Catastrophes and Earth History: The New Uniformitarianism. Princeton University Press, New York, 465 pp. 
Bray, J.R., 1964. Primary consumption in three forest canopies. Ecology 45, 165-167.

Broecker, W.S., Peng, T.-H., 1974. Gas exchange rates between air and sea. Tellus 26, 21-24.

Broecker, W.S., Peng, T.-H., Ostlund, G., Stuiver, M., 1985. The distribution of bomb radiocarbon in the ocean. J. Geophys. Res. 90, 6953-6970.

Budyko, M.I., Ronov, A.B., Yanshin, A.L., 1987. History of the Earth's Atmosphere. Springer-Verlag, Berlin, 139 pp.

Cross, M.C., Hohenberg, P.C., 1993. Pattern formation outside of equilibrium. Rev. Mod. Phys. 65, 851-1112.

Dawkins, R., 1982. The Extended Phenotype. Freeman, Oxford, 307 pp.

Degens, E.T., Kempe, S., Spitzy, A., 1984. Carbon dioxide: a biogeochemical portrait. In: Hutziger, O. (Ed.), The Handbook of Environmental Chemistry, vol. 1, part C. Springer-Verlag, Berlin, pp. 125-215.

Doolittle, W.F., 1981. Is nature really motherly? Coevolut. Q. 29, 58-63.

Døckersmith, I.C., Giardina, C.P., Sanford Jr., R.L., 1999. Persistence of tree related patterns in soil nutrients following slash-and-burn disturbance in the tropics. Plant Soil 209, 137156.

Farrar, J.F., 1976. The lichen as an ecosystem: observation and experiment. In: Brown, D.H., Hawksworth, D.L., Bayley, R.H. (Eds.), Lichenology: Progress and Problems. Academic Press, New York, pp. 385-406.

Fedorov, V.D., Gilmanov, T.G., 1980. Ekologiya. Moscow University Press, Moscow (in Russian).

Foley, J.A., Costa, M.H., Delire, C., Ramankutty, N., Snyder, P., 2003. Green surprise? How terrestrial ecosystems could affect Earth's climate. Front. Ecol. Environ. 1, 38-44.

Gorshkov, V.G., 1981. The distribution of energy flows among the organisms of different dimensions. J. Gen. Biol. 42, 417-429 (in Russian with English abstract).

Gorshkov, V.G., 1986. Biological and physical regulation of matter cycles. Izvest. (Proc.) All-Russ. Geogr. Soc. 118, 20-28 (in Russian).

Gorshkov, V.G., 1995. Physical and Biological Bases of Life Stability. Man, Biota, Environment. Springer-Verlag, Berlin, $340 \mathrm{pp}$.

Gorshkov, V.G., 1996. Stores and flows of information in biota and civilization. Dokl. Biol. Sci. 350, 469-471.

Gorshkov, V.G., Makarieva, A.M., 1997. Dependence of heterozygosity on body weight in mammals. Dokl. Biol. Sci. 355, 384-386.

Gorshkov, V.G., Makarieva, A.M., 2001. On the possibility of physical self-organization of biological and ecological systems. Dokl. Biol. Sci. 378, 258-261.

Gorshkov, V.G., Makarieva, A.M., 2002. Greenhouse effect dependence on atmospheric concentrations of greenhouse substances and the nature of climate stability on Earth. Atmos. Chem. Phys. Discuss. 2, 289-337.

Gorshkov, V.G., Sherman, S.G., 1986. Atmospheric $\mathrm{CO}_{2}$ and destructivity of the land biota: seasonal variations. Nuovo Cimento 9C (4), 902-917.
Gorshkov, V.G., Gorshkov, V.V., Makarieva, A.M., 2000. Biotic Regulation of the Environment: Key Issue of Global Change. Springer-Verlag, London, 367 pp.

Gorshkov, V.V., Gorshkov, V.G., Danilov-Danil'yan, V.I., Losev, K.S., Makarieva, A.M., 2002. Information in the animate and inanimate worlds. Russ. J. Ecol. 33, 149-155.

Gould, S.J., Eldridge, N., 1993. Punctuated equilibrium comes of age. Nature 366, 223-227.

Grodzinski, W., 1971. Food consumption of small mammals in the Alaskan taiga forest. Ann. Zool. Fenn. 8, 133-136.

Hayes, J.M., 1996. The earliest memories of life on Earth. Nature 384, 21-22.

Heinonsalo, J., Jørgensen, K.S., Sen, R., 2001. Microcosm-based analyses of Scots pine seedling growth, ectomycorrhizal fungal community structure and bacterial carbon utilization profiles in boreal forest humus and underlying illuvial mineral horizons. FEMS Microbiol. Ecol. 36, 73-84.

Hoffman, P.F., Kaufman, A.J., Halverson, G.P., Schrag, D.P., 1998. A Neoproterozoic snowball Earth. Science 281, 1342-1346.

Holmen, K., 1992. The global carbon cycle. In: Butcher, S.S., Charlson, R.J., Orians, G.H., Wolfe, G.V. (Eds.), Global Biogeochemical Cycles. Academic Press, London, pp. 239-262.

Hook, P.B., Burke, I.C., Lauenroth, W.K., 1991. Heterogeneity of soil and plant $\mathrm{N}$ and $\mathrm{C}$ associated with individual plants and openings in North American shortgrass steppe. Plant Soil 138, 247-256.

Humphreys, W.F., 1979. Production and respiration in animal populations. J. Anim. Ecol. 48, 427-453.

Ingersoll, A.P., 1969. The runaway greenhouse: a history of water on Venus. J. Atmos. Sci. 26, 1191-1198.

IPCC, 1996. In: Houghton, J.T., Meira-Filho, L.G., Callander, B.A., Harris, N., Kattenberg, A., Maskell, K. (Eds.), Climate Change 1995: The Science of Climate Change. Cambridge University Press, Cambridge, 572 pp.

Jackson, J.B.C., 1990. Evolutionary significance of morphospecies: a test with cheilostome Bryozoa. Science 248, 579-583.

Jackson, J.B.C., 1994. Constancy and change of life in the sea. Phil. Trans. R. Soc. Lond. B 344, 55-60.

Jerlov, N.G., 1976. Marine Optics. Elsevier Oceanography Series, vol. 14. Elsevier, Amsterdam, 231 pp.

Kobak, K.I., 1988. Biotic Components of the Carbon Cycle. Gidrometeoizdat, Leningrad, 230 pp. (in Russian).

Krauss, L.M., Chaboyer, B., 2003. Age estimates of globular clusters in the Milky Way: constraints on cosmology. Science 299, 65-69.

Kutzbach, J.E., 1985. Modeling of paleoclimates. Adv. Geophys. 28A, 159-196.

Landau, L.D., Lifshitz, E.M., 1987. Course of Theoretical Physics, vol. 6. Fluid Mechanics, second ed. Pergamon Press, Oxford, $539 \mathrm{pp}$.

Lenton, T.M., von Blohe, W., 2001. Biotic feedback extends the life span of the biosphere. Geophys. Res. Lett. 28, 1715-1718.

Lerat, S., Gauci, R., Catford, J.G., Vierheilig, H., Piché, Y., Lapointe, L., 2002. ${ }^{14} \mathrm{C}$ transfer between the spring ephemeral Erythronium americanum and sugar maple saplings via arbuscular mycorrhizal fungi in natural stands. Oecologia 132, $181-187$. 
Levitus, S., 1982. Climatological Atlas of the World Ocean. NOAA Professional Paper No. 13. US Government Printing Office, Washington, DC.

Lovelock, J., 1982. Gaia. A New Look at Life on Earth. Oxford University Press, New York, 157 pp.

Lovelock, J.E., 1995. The Ages of Gaia. A Biography of Our Living Earth. Norton, New York, 255 pp.

Makarieva, A.M., 2001. Variance of protein heterozygosity in different species of mammals with respect to the number of loci studied. Heredity 87, 41-51.

Makarieva, A.M., Gorshkov, V.G., Li, B.-L., in review. Body size, energy consumption and allometric scaling: a new dimension in the diversity-stability debate. Ecol. Complex.

Mitchell, J., 1989. The "greenhouse" effect and climate change. Rev. Geophys. 27, 115-139.

Nakajima, S., Hayashi, Y.-Y., Abe, Y., 1992. A study on the "runaway greenhouse effect" with a one-dimensional radiativeconvective equilibrium model. J. Atmos. Sci. 49, 2256-2266.

Odum, E.P., 1971. Fundamentals of Ecology. Saunders, Philadelphia, 574 pp.

Pennanen, T., Liski, J., Bååth, E., Kitunen, V.V., Uotila, J., Westman, C.J., Fritze, H., 1999. Structure of the microbial communities in coniferous forest soils in relation to site fertility and stand development stage. Microb. Ecol. 38, 168-179.

Pujol, T., North, G.R., 2002. Runaway greenhouse effect in a semigray radiative-convective model. J. Atmos. Sci. 59, 28012810.

Rasool, S.I., de Berg, C., 1979. The runaway greenhouse and the accumulation of $\mathrm{CO}_{2}$ in the Venus atmosphere. Nature 226, 1037-1039.

Raval, A., Ramanathan, V., 1989. Observational determination of the greenhouse effect. Nature 342, 758-761.

Rhoades, C.C., 1997. Single-tree influence on soil properties in agroforestry systems: lessons from natural and savanna ecosystems. Agrofor. Syst. 35, 71-94.

Robertson, D., Robinson, J., 1998. Darwinian daisyworld. J. Theor. Biol. 166, 365-373.

Russell-Hunter, W.D., 1970. Aquatic Productivity. Macmillan, New York, $306 \mathrm{pp}$.

Sathyendranath, S., Gouveia, A.D., Shetye, S.R., Ravindran, P., Platt, T., 1991. Biological control of surface temperature in the Arabian Sea. Nature 349, 54-56.

Saunders, P.T., 1994. Evolution without natural selection: further implications of the daisyworld parable. J. Theor. Biol. 166, 365-373.

Savin, S., 1977. The history of the Earth's surface temperature during the past 160 million years. Annu. Rev. Earth Planet. Sci. 5, 319-355.
Schwartzman, D., 1999. Life, Temperature, and the Earth: The Self-organizing Biosphere. Columbia University Press, New York, $241 \mathrm{pp}$.

Schwartzman, D.W., Volk, T., 1989. Biotic enhancement of weathering and the habitability of Earth. Nature 340, 457-460.

Shukla, J., Mintz, Y., 1982. Influence of land-surface evapotranspiration on the Earth's climate. Science 215, 1498-1500.

Siegenthaler, U., Sarmiento, J.L., 1993. Atmospheric carbon dioxide and the ocean. Nature 365, 119-125.

Staley, M., 2002. Darwinian selection leads to Gaia. J. Theor. Biol. $218,35-46$.

Stanley, S.M., 1979. Macroevolution: Pattern and Process. Freeman, San Francisco, 332 pp.

Steffen, W., Jäger, J., Carson, D.J., Bradshaw, C. (Eds.), 2003. Challenges of a Changing Earth. In: Proceedings of the Global Change Open Science Conference, Amsterdam, The Netherlands, 10-13 July 2001. Springer-Verlag, Berlin, 216 pp.

Turner II, B.L., 2003. Toward integrated land-change science: advances in 1.5 decades of sustained international research on land-use and land-cover change. In: Steffen, W., Jäger, J., Carson, D.J., Bradshaw, C. (Eds.), Challenges of a Changing Earth. Proceedings of the Global Change Open Science Conference, Amsterdam, The Netherlands, 10-13 July 2001. Springer-Verlag, Berlin, pp. 21-26.

van Zuilen, M.A., Lepland, A., Arrhenius, G., 2002. Reassessing the evidence for the earliest traces of life. Nature 418, 627-630.

Walker, J.C.G., Hays, P.B., Kasting, J.F., 1981. A negative feedback mechanism for the long-term stabilization of Earth's surface temperature. J. Geophys. Res. 86 (C10), 9776-9782.

Wardle, D.A., Yeates, G.W., Watson, R.N., Nicholson, K.S., 1995. The detritus food-web and diversity of soil fauna as indicators of disturbance regimes in agroecosystems. Oikos 73, 155-166.

Watts, J.A., 1982. The carbon dioxide question: data sampler. In: Clark, W.C. (Ed.), Carbon Dioxide Review. Clarendon Press, New York, pp. 432-469.

Whitman, W.B., Coleman, D.C., Wiebe, W.J., 1998. Prokaryotes: the unseen majority. Proc. Natl. Acad. Sci. U.S.A. 95, 65786583.

Whittaker, R.H., Likens, G.E., 1975. The biosphere and man. In: Lieth, H., Whittaker, R. (Eds.), Primary Productivity of the Biosphere. Springer-Verlag, Berlin, pp. 305-328.

Wiegert, R.G., Owen, D.F., 1971. Trophic structure, available resources and population density in terrestrial versus aquatic ecosystems. J. Theor. Biol. 30, 69-81.

Yeates, G.W., Bardgett, R.D., Cook, R., Hobbs, P.J., Bowling, P.J., Potter, J.F., 1997. Faunal and microbial diversity in three Welsh grassland soils under conventional and organic management regimes. J. Appl. Ecol. 34, 453-471. 